\title{
Los valores en la responsabilidad social en la educación superior
}

\author{
“En épocas de crisis, sólo la imaginación es más importante que el conocimiento"
} Albert Einstein

En la actualidad, la sociedad que está sumergida en una vorágine de cambios en todos los ámbitos, exigiendo nuevas adaptaciones al grupo humano para constituirse en eslabones que construyan el desarrollo de la población y de las personas de manera particular, requiere que se valore la trascendencia de la educación superior como cimiento de una sociedad más próspera, justa y solidaria.

Tünnermann ${ }^{1}$ señala que la educación superior en este siglo demanda flexibilización en su "hacer" y "quehacer", reformando sus estructuras y métodos de trabajo e integrando una visión prospectiva donde la imaginación y creatividad -inspirados en la solidaridad, equidad y respeto al medio ambiente- sean la base del proceso de aprendizaje de las personas; proceso que le facilitaría el ingreso al mundo laboral globalizado y, como miembro activo, para alcanzar los Objetivos de Desarrollo Sostenible del Milenio al 2030, los cuales constituyen propuestas a los grandes problemas que padece la población en esta era "sobre todo", América Latina y El Caribe.

En el 2008, la Conferencia Regional de la Educación Superior en América Latina y El Caribe, desarrollada como antesala a la Conferencia Mundial sobre la Educación Superior ejecutada en París el 2009, evidencia la necesidad de que la educación superior contribuya a la convivencia democrática y tolerante, con espíritu de solidaridad y de cooperación entre miembros; asimismo, fomenta oportunidades para que toda la humanidad, con énfasis en las poblaciones vulnerables, coadyuve en la creación del conocimiento, transformación social y productiva de las sociedades. $^{2}$

Ya en la Conferencia Mundial en París, es destacada la responsabilidad social que tienen las instituciones de educación superior, especificando entre otros puntos, que deben [...] contribuir a la formación de ciudadanos con principios éticos, comprometidos en la construcción de la paz, de los derechos humanos y los valores [...]. ${ }^{3} \mathrm{Necesidad}$ que es más latente en los pueblos del planeta donde las inequidades constituyen una brecha para convivir dignamente y que podría reducirse potencializando el conocimiento, en suma, el talento humano. En ese sentido, la educación en el siglo XXI busca afianzar en la persona la seguridad de que aun estando sumergida en los cambios que van sucediendo, su integridad cultural, su esencia de humano no se pierda; al contrario, busque herramientas que le ayuden a realizar su proyecto personal.

Es así que la universidad se ve sometida a profundos cambios, uno de ellos es la formación de competencias entendiendo que ésta involucra, además de los aspectos cognitivos y procedimentales, aspectos actitudinales en los que imperan los valores que deben cimentar o construir al discente como ser humano integro. Según, Casares et al., ${ }^{4}$ citando a Jover et al., refieren que las competencias constituyen una categoría específica de las características individuales que tienen lazos estrechos con los valores, la ética y los conocimientos adquiridos.

Desde esta visión integral, la competencia es un conjunto de conocimientos, actitudes, valores y habilidades que son necesarias para analizar situaciones específicas con pensamiento crítico que permita un desempeño satisfactorio desde una óptica humana, en las que atributos como la solidaridad, benevolencia, tolerancia, compasión por el prójimo reflejen que el profesional, además de aprender a ser, aprendió a convivir.

En tal sentido, los educadores del Milenio tienen la responsabilidad de formar personas con mentalidad amplia y flexible y convicciones profundas; personas dispuestas a servir a la humanidad en el lugar donde se encuentren, ${ }^{5}$ lo que exige una formación con fuerte contenido ético, valorativo y científico para lograr salir del subdesarrollo moral en el que está sumergido la humanidad o, como refiere García Serrano citando a Kant ${ }^{6}$, la educación del deber romperá estructuras mentales basadas en el facilismo, llevará al cumplimiento de las obligaciones, al respeto de los derechos humanos de los diferentes tipos de diversidad, a la construcción de un mundo en el que nuestras acciones permitan una 
convivencia armónica y sostenible, lo que podría traducirse en lo que Morín, citado por Romero et al., ${ }^{5}$ denomina el Quinto Nacimiento [...] posible pero todavía no probable, sería el nacimiento de la humanidad, que nos haría abandonar la edad de hierro planetaria, de la prehistoria del espíritu humano, que civilizaría la tierra y vería el nacimiento de la sociedad- mundo [...].

Lograr esa prosperidad moral implica una constelación de virtudes, como bien lo señalaba Juan Pablo II: laboriosidad, orden, honestidad, iniciativa, ahorro, espíritu de servicio, cumplimiento de la palabra empeñada; en suma, amor al trabajo bien hecho. ${ }^{7}$ Como se ve, es ardua la labor del educador de este siglo, ya que no sólo debe lograr la capacitación de sus estudiantes, también debe formar personas, hacerlas crecer y desarrollar en ellas capacidades para la vida.; la educación debe centrarse en la formación humana [...] El educador para el siglo XXI, escribe el profesor colombiano Alvaro Recio, será un pedagogo-investigador con una honda formación humana y social, de modo que se convierta en agente de cambio de él mismo, de sus alumnos y de la comunidad circundante [...]. ${ }^{1}$

\section{REFERENCIAS BIBLIOGRÁFICAS}

1. Tünnermann BC. El rol del docente en la educación superior del siglo XXI [internet]. México: UNAM; 20 nov 2009 [citado 10 may 2017]. p.17. Disponible en: https://es.scribd.com/document/264718933/EL-ROL-DEL-DOCENTEEN-LA-EDUCACION-SUPERIOR-DEL-SIGLO-XXI

2. Conferencia Regional sobre la Educación Superior en América Latina y El Caribe (CRES). Declaraciones y Plan de Acción. Perfiles Educativos [serie de internet]. Ene 2009 [citado 02 may 2017]; 31 (125): 90-108. Disponible en: http://www.scielo.org.mx/pdf/peredu/v31n125/v31n125a7.pdf

3. UNESCO. Conferencia Mundial sobre la Educación Superior-2009: La nueva dinámica sobre la educación superior y la investigación para el cambio social y desarrollo [internet]. Paris: UNESCO; 08 jul 2009 [citado 10 de abr 2017]. p.09. Disponible en: http://www.unesco.org/education/WCHE2009/comunicado_es.pdf

4. Casares GPM, Carmona OG, Martínez-Rodríguez FM. Valores profesionales en la formación universitaria. REDIE [serie de internet]. Ene 2010 [citado 15 de abr 2017]; 12(Esp): [cerca de 15c laudas]. Disponible en: http://www.scielo.org.mx/pdf/redie/v12nspe/v12nspea4.pdf

5. Romero IPJ (Coord). Pedagogía de la humanización [internet]. Colombia: Universidad San Buenaventura, Facultad de Educación; may 2006 [citado 02 de may 2017]. p. 28. Disponible en: http://biblioteca.usbbog.edu.co:8080/Biblioteca/BDigital/36711-01.pdf

6. García SSE. Referentes epistemológicos para la competencia: actuar éticamente como ciudadano y profesional. Rev Temas [serie de internet]. 2016 [citado 21 may 2017]; 3(10): 111-120. Disponible en: https://dialnet.unirioja.es/descarga/articulo/5894412.pdf.

7. Pablo II J. Discurso del Santo Padre Juan Pablo II a los delegados de la comisión económica para América Latina y El Caribe (CEPALC) [internet]. Santiago de Chile: LÓsservatore Romano; abr 1987 [citado 16 de abr 2017 ]. p. 02. Disponible en: https://w2.vatican.va/content/john-paul-ii/es/speeches/1987/april/documents/hf_jpii_spe_19870403_cepalc-chile.html

María Inés Ruiz Garay ${ }^{1, a, b}$

1 Escuela de Enfermería Padre Luis Tezza afiliada a la Universidad Ricardo Palma, Lima-Perú.

a Licenciada en Enfermería.

b Magister en Enfermería, con mención en Gestión Administrativa. 